\title{
Differences in walking attainment ages between low-risk preterm and healthy full-term infants
}

\author{
Diferenças na idade de aquisição da marcha entre lactentes pré-termo \\ de baixo risco e a termo saudáveis
}

Ana P. Restiffe', José Luiz D. Gherpelli²

\begin{abstract}
Objective: To compare gross motor development of preterm infants (PT) without cerebral palsy with healthy full-term (FT) infants, according to Alberta Infant Motor Scale (AIMS); to compare the age of walking between PT and FT; and whether the age of walking in PT is affected by neonatal variables. Methods: Prospective study compared monthly 101 PT and 52 FT, from the first visit, until all AIMS items had been observed. Results: Mean scores were similarity in their progression, except from the eighth to tenth months. FT infants were faster in walking attainment than PT. Birth weight and length and duration of neonatal nursery stay were related to walking delay. Conclusion: Gross motor development between PT and FT were similar, except from the eighth to tenth months of age. PT walked later than FT infants and predictive variables were birth weight and length, and duration of neonatal intensive unit stay.
\end{abstract}

Key words: Alberta Infant Motor Scale, child development, infant, premature, motor activity.

\section{RESUMO}

Objetivo: Comparar o desenvolvimento motor de lactentes pré-termo sem paralisia cerebral (PT) com lactentes normais nascidos a termo (T), de acordo com Escala Motora Infantil de Alberta (AIMS); comparar idade da marcha entre PT e Te se a idade da marcha em PT é passível de ser afetada. Métodos Estudo prospectivo com 101 PT e 52 T, seguidos mensalmente até que todos os itens da AIMS tivessem sido observados. Resultados: Os escores médios apresentaram semelhanças entre os grupos, com exceção do oitavo ao décimo meses. Os lactentes T iniciaram marcha antes dos PT. Peso, estatura ao nascimento e tempo de internação na unidade de terapia intensiva neonatal (UTIN) foram preditivos. Conclusão: O desenvolvimento motor entre PT e T foi semelhante, exceto entre o oitavo e o décimo meses de idade. PT andaram mais tardiamente e variáveis preditivas foram peso, estatura ao nascimento e o tempo de permanência na UTIN.

Palavras-Chaves: Escala Motora Infantil de Alberta, desenvolvimento infantil, lactente, prematuro, atividade motora.

During the past decades there was an increase in the survival rate of infants born very preterm (gestational age <32 weeks) and with very low birth weight (VLBW). However, this was associated with an increased rate of adverse developmental outcome, which in turn has raised important issues regarding the quality of life of these infants ${ }^{1}$.

The incidence cerebral palsy $(\mathrm{CP})$ ranges from 5 to $15 \%$ and is inversely related to birth weight and gestational age. $\mathrm{CP}$ is often detected during the first year of life ${ }^{2}$. Minor neurological dysfunctions (MND) such as motor coordination disorder or clumsiness, behavioral problems, and learning disorders range from 40 to $70 \%$ and usually become more apparent as the child grows older ${ }^{3}$.

Whether delay in achieving developmental milestones is a marker of $\mathrm{MND}^{4}$ or a variation of normal motor development in preterm infants is a matter still under debate ${ }^{5}$. Developmental abnormalities and delays diagnosed early in life in preterm infants may be transient and may fade away as a result of the interaction between genetic and environmental factors ${ }^{6}$, and also the interaction of various systems, including the neuromuscular, sensory, biomechanical, and central nervous systems ${ }^{7}$.

\footnotetext{
1Physical Therapist (PT) ScD; Department of Neurology, Medical School, Universidade de São Paulo (USP), São Paulo SP, Brazil;

${ }_{2}^{2}$ Pediatric Neurologist (MD) PhD; Department of Neurology, Medical School, USP, São Paulo SP, Brazil.

Correspondence: Ana P. Restiffe; Rua Lourenço de Almeida 772/51;04508-001 São Paulo SP - Brasil; E-mail: aprestiffe@sgl.com.br

Support: This study was supported by Fundação de Amparo à Pesquisa do Estado de São Paulo (FAPESP), Process nº 04/15332-0; Ana P. Restiffe received a scholarship grant from (CAPES).

Conflict of interest: There are no conflicts of interest to declare.

Received 19 February 2012; Received in final form 03 April 2012; Accepted 10 April 2012
} 
Walking is considered an important motor developmental milestone and has a predictive value for future motor abilities, but virtually nothing is known about such relationship ${ }^{8}$. Studies that compared walking onset ages between preterm infants without major neurological disabilities and normal full-term infants were inconclusive ${ }^{9-14}$. Some studies showed that preterm infants walk at older ages ${ }^{10-12,14}$, while others reported walking at similar ages as term infants ${ }^{9,13}$. Normal fullterm infants usually attain independent walking at about 12 months of age, and continuously refine their movement in the following years to establish a mature walking pattern ${ }^{8,9,14}$. Accumulating data on preterm infants have shown that the measure of age at onset of walking reflects various degrees of motor delay ${ }^{8-10,14}$. These findings suggest that age at onset and quality of walking movement may be useful measures for diagnosing future minor motor abnormalities in preterm infants ${ }^{14}$.

We hypothesized that infants born preterm without major neurological disabilities have a different pattern of early gross motor development compared to healthy full-term infants. More specifically, the onset of independent walking among preterm infants is later than full-term infants. We also hypothesized that these variations are related to specific biological and/or non-biological variables, considered in this investigation as predictor variables.

Herein the objectives of this study were: to compare prospectively gross motor performance of preterm infants with low risk for major neurological disabilities with healthy full-term infants based on the Alberta Infant Motor Scale $(\text { AIMS })^{15}$, to compare the age at onset of independent walking between low risk preterm infants and healthy infants born at term and to investigate whether the age of onset walking in infants born preterm was affected by perinatal and/or sociodemographic variables.

\section{METHODS}

From June 2004 to August 2005, the researcher (A.P.R.) recruited and assessed consecutively and in a non-randomized way, 101 preterm infants with low risk for neurological problems, and 52 healthy full-term infants, at the first hospital follow-up visit. Preterm and full-term infants were followed prospectively and examined monthly, until 18 months of corrected and chronological age, respectively. At this age, all infants underwent a full neurologic evaluation performed by a neurologist (J.L.D.G.) to exclude a major neurological abnormality (cerebral palsy, severe motor delay, reflex abnormality, muscle tone abnormality, focal neurological signs, persisting asymmetry, or seizures).

All preterm infants were inborn at the Clinics Hospital of the Universidade de São Paulo (USP) Medical School. Inclusion criteria were: gestational age (GA) <37 weeks and the mother's willingness to participate in the study. Exclusion criteria were: presence of congenital or chromosomal anomalies and major neonatal diseases that could impair neurodevelopment, such as grade III and IV intraventricular hemorrhages ${ }^{16}$, periventricular leukomalacia, moderate or severe hypoxic ischemic encephalopathy ${ }^{17}$, meningitis, encephalitis and cerebral malformation, severe retinopathy of prematurity (stage III-IV), visual and hearing deficits, seizures, and absence on more than three consecutive appointments.

Full-term infants were born at the Hospital of the USP. The inclusion criteria were: singleton, inborn, gestational age between 37 and 42 weeks, Apgar score $>5$ points at 10 minutes, birth weight $\geq 2.5 \mathrm{~kg}$ and absence of maternal and perinatal complications and of significant medical problems in the neonatal period and/or during the follow-up period, plus mother's willingness participate in the study. The exclusion criteria were: presence of abnormal neurological impairments during follow-up or at 18 month chronological-age; presence of delay in the spheres of adaptive, language, and social development; and failure to attend more than three consecutive appointments.

We defined independent walking onset as the moment when the infants were able to move for five successive steps without support ${ }^{15}$.

If an abnormal neurological impairment was detected during follow-up and/or at 18 months of corrected and chronological age the child was excluded. None of children underwent rehabilitation during follow-up.

Gestational age (GA) was estimated based on the date of the mother last menstrual period and confirmed by early ultrasound scan performed before 20 weeks of gestation. Some cases had their GA estimated by the New Ballard assessment ${ }^{18}$ scores (preterm infants) or by the Capurro ${ }^{19}$ assessment (at term). Corrected age was calculated by subtracting to the degree of prematurity from the chronological age and was used during the study period for all preterm infants.

This study was approved by the Ethics Committees of University Hospital of the USP and the Clinics Hospital of the University of São Paulo Medical School, Brazil before recruitment of participants. All parents signed an informed consent form.

Monthly evaluation assessments were scheduled, either at home or at the hospital, depending on parent's convenience. One of the authors (A.P.R.), who had been trained for reliability for research use and had achieved $82 \%$ of agreement, in a pilot-study which took place before the data collection of the present study, was the only investigator to interact with the child, apart from the parents. Infant motor performance was recorded through videotape that lasted between 20 and 40 minutes and displayed the motor performance repertoire in four positions (prone, supine, sitting, and standing). During the assessment, the infants were laid undressed either on the examining table or on a firm mat. Neither facilitation nor handling was allowed. In order to motivate the infants to move and explore the environment, verbal cues and toys were used. All videotapes recorded were 
replayed thoroughly, without being edited, so that the only investigator could score the infant motor function, according to the AIMS assessment tool criteria ${ }^{15}$.

Perinatal data were collected from medical records. Socioeconomic variables included race and mother's education and occupational level and socioeconomic classification. The latter was expressed as four indicators: family's monthly income according to multiples of one minimum monthly wage, household resources, housing quality, and parental literacy ${ }^{20}$.

\section{Statistical analysis}

A total sample size of 40 infants was needed to demonstrate comparison group differences in the age of walking attainment equal or greater than two months. It was assumed that all infants (preterm and full term) had a constant chance of a specific event (i.e. independent walking attainment) to happen throughout the observation period. The power of the study was $90 \%$ and the significance level was 0.05 .

For each month, individual full-term and preterm infants' AIMS raw scores according to chronological and corrected ages, were clustered to calculate monthly mean $\operatorname{scores}^{21}$. To demonstrate statistical difference between the groups, the variability in the AIMS mean scores was measured by calculating monthly standard error. If monthly standard error scores between comparison groups overlapped, it indicated absence of statistical difference in the AIMS scores between the groups in that specific month. The AIMS mean score was calculated only until children reached 16 months of corrected age because after that almost all infants had completed all the 58 AIMS items.
Walking onset age between preterm and full-term infants was estimated by Kaplan-Meier function and Turnbull methods ${ }^{21}$.

The relationships between independent variables (perinatal and/or socio-demographic and walking attainment age) were analyzed using Cox's proportional hazard regression models.

Statistical analyses were performed using SPSS version 10.0, Microsoft Excel version 2002, MINITAB version 14, R version 2.2.0, and SAS System, version 8.0.

\section{RESULTS}

\section{Sample characteristics}

Forty-nine full-term infants and 77 preterm infants completed the study. All infants had a normal neurological examination at 18 months. Three full-term infants were excluded from the study; 2 were lost to follow-up and 1 had a mild motor delay at 18 months. Twenty-four preterm infants were excluded: ten infants $(10 / 24 ; 42 \%)$ were diagnosed as having cerebral palsy; six preterm infants $(6 / 24 ; 25 \%)$ were still not walking at the end of the study period; two infants $(2 / 24 ; 8.5 \%)$ died and two $(2 / 24 ; 8.5 \%)$ were lost to follow-up. There were four pairs of identical twins and one infant of each pair $(4 / 24 ; 16 \%)$ was randomly excluded, due to sibling dependence.

Table 1 shows perinatal characteristics of full-term and preterm infants and preterm perinatal morbidities which variables were also used in the Cox's proportional hazard regression models. Analysis of socioeconomic characteristics revealed similarly distribution across the studied groups as shown in Table 2.

Table 1. Perinatal characteristics of full-term and preterm infants and preterm perinatal morbidities.

\begin{tabular}{lcc} 
Variables & Full-term & Preterm \\
\hline Total (\%) & $49(100)$ & $77(100)$ \\
Mean gestational age (range) (weeks) & $39.6(37.1-42.0)$ & $31.9(25.7-36.0)$ \\
Moderate premature (\%)/extreme premature (\%) & - & $30(39) / 36(47)$ \\
Mean birth weight (range) (grams) & $3,178(2,500-4,020)$ & $1,505 g(590-2,500)$ \\
Low birth weight (\%)/Very-low birth weight (\%) & - & $33(43) / 31(40)$ \\
Mean birth stature (range) (cm) & $49(44-52)$ & $39(30-47)$ \\
Birth head circumference (range) (cm) & $34(32-37)$ & $29(23-33)$ \\
1-minute Apgar score median (range) & $9(5-7)$ & $7(1-10)$ \\
5-minute Apgar score median (range) & $9(6-10)$ & $8(3-10)$ \\
Gestational age vs. birth weight & & $49(64)$ \\
$\quad$ Adequate for gestational age (\%) & $47(96)$ & $28(36)$ \\
Small for gestational age (\%) & $2(4)$ & 4.4 days (0-78) \\
Mean duration of mechanical ventilation (range) & 0 day (0) & 40 days (2-125) \\
$\quad$ Mean duration of neonatal nursery stay (range) & 3 days (2-13) & $49(64)$ \\
Number of hospital admission & & $27(35)$ \\
$\quad$ None (\%) & $40(82)$ & $1(1)$ \\
Once (\%) & $8(16)$ & $63(82)$ \\
Twice (\%) & $1(2)$ & $20(26)$ \\
Neonatal respiratory distress (\%) & & $11(14)$ \\
Hyaline membrane disease (\%) & & $23(30)$ \\
Bronchopulmonary dysplasia (\%) & & $20(26)$ \\
Intraventricular hemorrhage (grades I and II) (\%) & & \\
Retinopathy of prematurity (I and II) (\%) & & \\
\hline
\end{tabular}


Table 2. Socio-demographic characteristics of full-term and preterm infants.

\begin{tabular}{|c|c|c|c|}
\hline Variables & Full-term (\%) & Preterm (\%) & $\mathrm{p}$-value \\
\hline Total & $49(100)$ & $77(100)$ & \\
\hline Male gender & $25(51)$ & $43(56)$ & 0.6978 \\
\hline Caucasian & $25(51)$ & $41(53)$ & 0.9378 \\
\hline \multicolumn{4}{|l|}{ Maternal education } \\
\hline Incomplete elementary grade & $2(4)$ & $25(32)$ & 0.3223 \\
\hline Complete elementary grade* & $6(12)$ & $6(8)$ & \\
\hline Incomplete high school & $6(12)$ & $14(18)$ & 0.8217 \\
\hline Complete high school & $12(25)$ & $27(35)$ & \\
\hline Incomplete college level & $17(35)$ & $3(4)$ & \\
\hline College level & $6(12)$ & $2(3)$ & \\
\hline \multicolumn{4}{|l|}{ Maternal occupation } \\
\hline Unemployed/housewife** & $29(59)$ & $46(60)$ & 0.5025 \\
\hline Unskilled labor & $15(31)$ & $24(31)$ & \\
\hline Technical labor & $3(6)$ & $4(5)$ & \\
\hline Professional & $2(4)$ & $3(4)$ & \\
\hline \multicolumn{4}{|l|}{ Socioeconomic status (family income) } \\
\hline B1-B2 (US\$ 532.5-1,471.50 per month)*** & $4(8)$ & $4(6)$ & 0.8484 \\
\hline C (US\$248.5-532.00 per month) & $27(55)$ & $35(45)$ & \\
\hline D (US\$248.00-131.50 per month) & $17(35)$ & $35(45)$ & \\
\hline E ( US\$131.00 per month) & $1(2)$ & $3(4)$ & \\
\hline
\end{tabular}

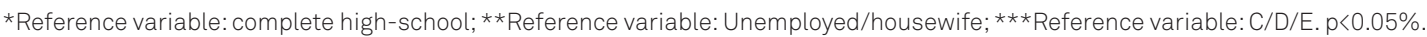

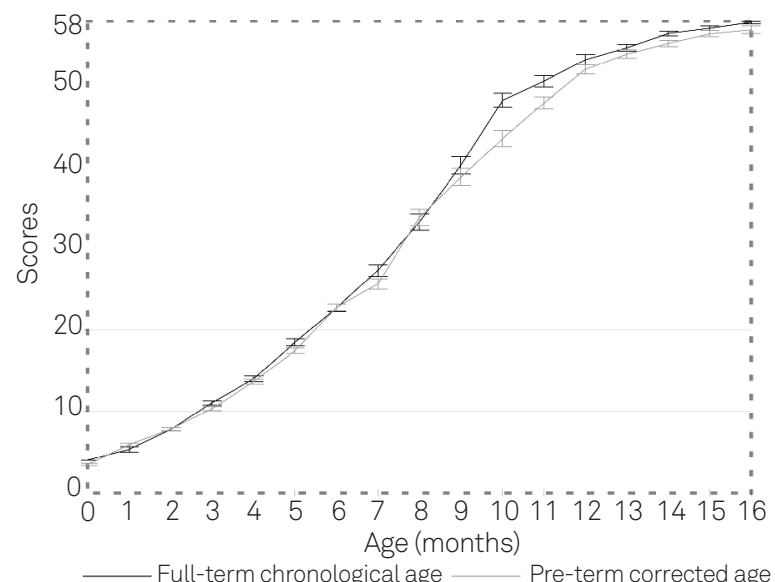

Fig 1. Progression of the Alberta Infant Motor Scale mean scores (one standard error) of full-term and preterm infants.

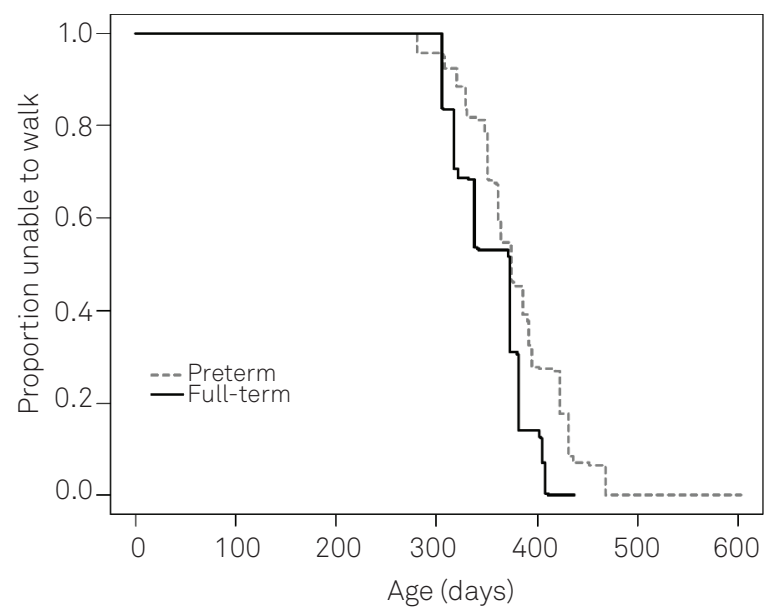

Fig 2. Kaplan-Meier estimates of proportion of infant unable to take five steps unaided.

\section{Longitudinal Alberta Infant Motor Scale scores}

Fig 1 shows the mean and standard error score of the AIMS curves of preterm versus full-term infants throughout the follow-up period. Both curves were similar in their progression pattern. Full-term infants mean scores were higher than those for preterm infants during follow-up, except in the first month. The greatest difference in scores between groups was observed from the $8^{\text {th }}$ to the $11^{\text {th }}$ months. From the $12^{\text {th }}$ up to the $16^{\text {th }}$ month, the difference gradually decreased. Fig 1 shows that there was less variability in AIMS scores in the first 6 months for both infant groups, while the greatest variability was observed from 7 to 12 months. From this point onwards, the variability tended to decrease as the infants reached the end of the evaluation. Fig 1 shows that the AIMS standard errors overlapped throughout the follow-up period, with the exception of the eighth, ninth, and tenth months of age.

\section{Predictive value of multiple variables on walking attainment}

Fig 2 shows Kaplan-Meier function plots of age of walking attainment distribution for preterm and full-term infants. Fig 2 shows that full-term infants were faster in walking attainment than preterm infants. Mean age of onset of walking among full-term was 368.6 days (299-436), whereas among preterm it was 381.6 days (288-470). The difference remained significant when $95 \%$ confidence interval age of walking attainment between preterm and full-term infants was estimated (95\%CI -1.268-0.162; $\mathrm{p}<0.05)$. The percentage of likelihood ratio of full-term infant to walk earlier than preterm is $51 \%$ (risk ratio $=1.51 ; 95 \%$ CI 1.176-3.554).

Regarding mean age at the first assessment among fullterm and preterm infants was respectively, 45 days (21-111) and 75 days (11-164), while mean age of completing all 58 
AIMS items among full-term and preterm infants was respectively, 414.6 days (333-488) and 424.3 days (328-526).

The perinatal independent variables that were statistically significant related to walking attainment delay were: birth weight $(p<0.0022)$, birth length $(p<0.022)$, and duration of neonatal nursery stay $(\mathrm{p}<0.0465)$. None of the socioeconomic variables were statistically related to walking attainment delay (p-value in Table 2).

Univariate proportional hazard regression analysis of perinatal risk factors for late walking attainment among preterm infants showed that a $100 \mathrm{~g}$ increment in birth weight increases by $11 \%$ the likelihood ratio of walking attainment (risk ratio=1.108; 95\%CI 1.044-1.170) and an $1 \mathrm{~cm}$ increment to birth length increases in $12 \%$ the likelihood ratio of walking attainment (risk ratio=1.116; 95\%CI 1.033-1.207). A decrease of 10 days of neonatal nursery stay increases by $14 \%$ the likelihood ratio of walking attainment (risk ratio=1.137; 95\%CI 1.025-1.260).

\section{DISCUSSION}

We identified differences in early gross motor development between low risk preterm infants compared with normal full-term infants. There was no statistical difference between preterm and full-term infant AIMS mean scores, with the exception of the eighth, ninth and tenth month periods.

Comparison of the AIMS scores between the preterm and full-term groups was previously reported ${ }^{11,22-26}$, however the methodologies were distinct among studies, jeopardizing data comparison.

Formiga and Linhares ${ }^{24}$ found that the preterm infants presented greater delay in the AIMS mean scores, especially from 9 to 12 months, while van Haastert et al..$^{22}$ reported significantly lower mean scores at all age levels. In a previous study ${ }^{25}$, we did not find statistical differences in the AIMS mean scores between the preterm infant group and the AIMS normative data, during the first year of life.

Regarding the study design, we followed our infants longitudinally from the first hospital visit until all infants had completed the 58 AIMS items and had undergone a comprehensive neurological examination. As we intended to draw the typical motor development pattern of the preterm infants over time, we chose to test both infant groups monthly, rather than doing it twice ${ }^{5}$ or at every three months up to 18 months $^{23}$. Interestingly, we found differences between the groups only at eight, nine, and ten months, when preterm infant mean scores were statistically lower than full-term infants'. A longitudinal study of infant performance on the AIMS revealed that measurements (raw scores, percentile ranks) varied from age to age with no systematic pattern within individual infants ${ }^{27}$. Therefore, this finding may suggest that preterm infants have a different pattern of score progression than full-term infants, which could be a biological variability between preterm and full-term infants. Alternatively, it is possible that the period between the $8^{\text {th }}$ and $12^{\text {th }}$ months is of special importance for early gross motor development due to the greatest score increase and the greatest difference in mean scores between our comparison groups. Darrah et al. ${ }^{27}$ observed that the rate of motor development in normal developing infants is characterized by within-subject variability and non-linearity of skill emergence. There are peaks, valleys, and plateaus in the neuro-developmental trajectories of standardized measures to provide information about child skill development, which indicates periods of acceleration, deceleration, or quiescence of activity.

Preterm infant motor trajectories resemble those of fullterm infants, as characterized by gradual increase in the AIMS scores with advancing age, alternating with periods of more or less quiescence. Both of our groups exhibited the greatest score increase between the $8^{\text {th }}$ and $12^{\text {th }}$ months of age. In the first three months and between the $12^{\text {th }}$ and $16^{\text {th }}$ months, the score slope of preterm infants showed a slow increase with a tendency of quiescence, characterized by attainment of few new motor skills. The small score increase or variation is limited towards the two ends of the measurement (in the first trimester and from 12 to 16 months), whereas the period between 8 and 12 months shows greater score variation. During this period, the AIMS items aggregate at the middle range of difficulty level, which suggests that the AIMS is sufficiently precise to discriminate among infants whose ability levels are in the middle range, but not at the lowest nor at the highest ability ends. Small score variation in the first three months may be due to the fact that there are only a few items in prone and supine positions that are commonly observed in infants at this age. However, after walking attainment (between 12 and 16 months), there are only standing items available to complete the 58 items $^{28}$.

Alternatively, this variability in the AIMS scores in these specific months may be related to limitations of the scaling of the AIMS items, as there is a discontinuity in item difficulty ${ }^{28}$. There are gaps at several difficulty levels, which indicate that a large jump in ability level is required to pass one or more items around the gap.

We observed delay of approximately one month in walking attainment among preterm infants (the mean age of onset walking in preterm: 381.6 days; and in fullterm infants: 368.6 days), which agreed with some studies $^{8,13,14}$. The age of onset of walking of our full-term infants was close to that reported by Allen and Alexander ${ }^{9}$. Some studies ${ }^{8,12}$ suggested that the age of walking attainment is related to the rate of maturation and development of nervous and musculoskeletal systems and therefore it may have some predictive value as a later neuromotor outcome measure. It is suggested for future research that the late walkers should be followed up to 4-5 years 
to verify the predictive value in other areas of the neuromotor development. Johnson, Goddard and Ashurst ${ }^{12}$ observed that more than half of the late walkers had an associated neurological abnormality diagnosed before the age of 3 , whereas $15 \%$ had no neurological dysfunction. It is a matter of speculation whether delay in walking among extremely low birth weight children can indicate subtle damage to motor control functions seen in "soft" or MND. Bartlett et al. ${ }^{29}$ reported that a significant proportion of children born preterm without major neurological condition were delayed in the acquisition of antigravity postural control and motor development, such as walking milestone. We found that birth weight and length and duration of nursery stay in the neonatal period had strong association with delay in preterm walking attainment.
Our results agree with studies ${ }^{10,11,30}$ that found a negative relation between late attainment of walking and extreme prematurity, small-for-gestational-age, and very-low birth weight infants.

We conclude that preterm infants walk later than fullterm infants, and that very low birth weight and length, and duration of neonatal nursery stay were predictive of late walking in preterm infants.

\section{ACKNOWLEDGMENTS}

To Applied Statistics Center (CEA), from Statistics and Mathematics Institute of Universidade de São Paulo (IMEUSP) and all infants and their families.

\section{References}

1. Wilson-Costello D. Is there evidence that long-term outcomes have improved with intensive care? Semin Fetal Neonatol Med 2007;12:344-354.

2. Han TR, Bang MS, Lim JY, Yoon BH, Kim IO. Risk factors of cerebral palsy in infants. Am J Phys Med Rehabil 2002;81: 297-303.

3. Hadders-Algra M. Two distinct forms of neurological dysfunction: perspectives emerging from review of data of the Groningen Perinatal Project. Dev Med Child Neurol 2002;44:561-571.

4. Marlow N, Henessy EM, Bracelwell MA, Wolke D, EPICure Study Group. Motor and executive function at 6 years of age after extremely preterm birth. Pediatrics 2007;120:793-804.

5. Piper MC, Byrne PJ, Darrah J, Watt MJ. Gross and fine motor development of preterm infants at eight and 12 months of age. Dev Med Child Neurol 1989;31:591-597.

6. Vaivre-Douret L, Ennouri K, Jrad I, Garrec C, Papiernik E. Effect of positioning on the incidence of abnormalities of muscle tone in lowrisk infants. Eur J Paediatr Neurol 2004;8:21-34.

7. Kamm K, Thelen E, Jensen JL. A dynamical system approach to motor development. Phys Ther 1990;70:763-775.

8. Kokubun M, Haishi K, Okuzumi H, Hosobuchi T, Koike T. Predicitive value of age of walking for later motor performance in children with mental retardation. J Intellect Disabil Res 1996;40:529-534.

9. Allen MC, Alexander GR. Screening for cerebral palsy in preterm infants: delay criteria for motor milestones attainment. J Perinatol 1994;14:190-193.

10. Largo RH, Molinari L, Weber M, Pinto LC, Duc G. Early development of locomotion: significance of prematurity, cerebral palsy and sex. Dev Med Child Neurol 1985;27:183-191.

11. Jeng S, Yau K, Liao H, Chen L, Chen P. Prognostic factors for walking attainment in very low-birthweight infants. Early Hum Dev 2000;59:159-173.

12. Johnson A, Goddard O, Ashurst $H$. Is late walking a marker of morbidity? Arch Dis Child 1990;65:486-488.

13. De Groot L, de Groot CJ, Hopkins B. An instrument to measure independent walking: are there differences between preterm and fullterm infants: J Child Neurol 1997;12:37-41.

14. Jeng SF, Lau TW, Hsieh WS, et al. Development of walking in preterm and term infants: age of onset, qualitative features and sensitivity to resonance. Gait Posture 2008;27:340-346.

15. Piper MC, Darrah J. Motor assessment of the developing infant. Philadelphia:W.B. Saunders, 1994
16. Papile LA, Burstein J, Burstein R, Koffler H. Incidence and evolution of subependymal and intraventricular hemorrhage: a study of infants with birth-weights less than 1,500 gm. J Pediatr 1978;92:529-534.

17. Sarnat HB, Sarnat MS. Neonatal encephalopathy following fetal distress: a clinical and eletroencephalographic study. Arch Neurol 1976;33:696-705.

18. Ballard JL, Khoury JC, Wedig K, Wang L, Eliers-Walsman BL, Lipp R. New Ballard Score: expanded to include extremely premature infants. J Pediatr 1991;119:417-423.

19. Capurro H, Korichzky S, Fonseca O, Caldeiro-Barcia R. A simplified method for diagnosis of gestational age in the newborn infant. $J$ Pediatr 1978;93:120-122.

20. Rutter M. Pesquisa de mercado. São Paulo: Ática, 1988.

21. Lee ET. Statistical methods for survival data analysis. Belmont: Wadsworth, 1980.

22. van Haastert IC, de Vries LS, Helders PJM, Jognmans MJ. Early gross motor development of preterm infants according to the Alberta Infant Motor Scale.J Pediatr 2006;149:617-622.

23. Pin TW, Eldridge B, Galea MP. Motor trajectories from 4 to 18 months corrected age in infants born at less than 30 weeks of gestation. Early Hum Dev 2010;86:573-580.

24. Formiga CKMR, Linhares MBM. Motor development curve from 0 to 12 months in infants born preterm. Acta Paediatr 2011;100:379-384.

25. Restiffe AP, Gherpelli,JLD. Comparison of chronological and corrected ages in the gross motor assessment of low-risk preterm infants during the first year of life. Arq Neuropsiquiatr 2006;64:418-425.

26. Giachetta L, Nicolau CM, Costa, APBM, Zuana AD. Influência do tempo de hospitalização sobre o desenvolvimento neuromotor de recémnascidos pré-termo. Fisioter Pesq 2010;17:24-29.

27. Darrah J, Redfern L, Maguire TO, Beaulne AP. Intra-individual stability of rate of gross motor development in full term infants. Early Hum Dev 1998;52:169-179.

28. Liao PM, Campbell SK. Examination of item structure of the Alberta Infant Motor Scale. Pediatr Phys Ther 2004;16:31-38.

29. BartlettDJ,FanningJK, Miller L, Conti-BeckerA, DoralpS. Development of the Daily Activities of Infant Scale: a measure supporting early motor development. Dev Med Child Neurol 2008;50:613-617.

30. Marín Gabriel MA, Pallás Alonso CR, De La Cruz Bértolo J, et al. Age of sitting unsupported and independent walking in very low birth weight preterm infants with normal motor development at 2 years. Acta Paediatr 2009;98:1815-1821. 